\title{
Pringy (Haute-Savoie)
}

Nord (chef-lieu)

\section{Karine Raynaud}

\section{(2) OpenEdition}

12 Journals

Édition électronique

URL : http://journals.openedition.org/adlfi/6918

ISSN : 2114-0502

Éditeur

Ministère de la culture

Référence électronique

Karine Raynaud, «Pringy (Haute-Savoie) », ADLFI. Archéologie de la France - Informations [En ligne], Rhône-Alpes, mis en ligne le 01 mars 2007, consulté le 27 avril 2019. URL : http:// journals.openedition.org/adlfi/6918

Ce document a été généré automatiquement le 27 avril 2019

(c) Ministère de la Culture et de la Communication, CNRS 


\title{
Pringy (Haute-Savoie)
}

\author{
Nord (chef-lieu)
}

\section{Karine Raynaud}

\section{Identifiant de l'opération archéologique : 229670}

Date de l'opération : 2007 (EX)

1 Une opération archéologique de diagnostic a été menée en prévision de l'aménagement de huit immeubles au nord du bourg, à proximité d'un vaste ensemble architectural antique.

Quarante-trois tranchées ont été ouvertes sur l'emprise de $19162 \mathrm{~m}^{2}$; elles ont dévoilé une armature géologique morainique couverte d'un modeste manteau colluvial argileux et une mise en valeur de ces terrains à plusieurs époques distinctes.

Des vestiges antiques bâtis occupent le quart sud-est de l'emprise et comprennent en particulier un bâtiment quadrangulaire de $10 \mathrm{~m}$ de côté dont ne sont connus que de courts segments des fondations. D'autres murs maçonnés lui répondent mais sans lien direct ou lisible; l'un d'entre eux est particulièrement long $(40 \mathrm{~m})$ et pourrait correspondre à un enclos de villa ou une limite parcellaire. Les axes du bâti antique sont confirmés par ces vestiges. Un caniveau couvert court à quelques mètres au nord du bâtiment.

4 Si d'autres vestiges se rapportent vraisemblablement au même cadre chronoculturel, ils n'ont pas pu être distingués de la trentaine de structures en galets disséminées sur les deux hectares sondés. Des empierrements, des alignements de galets, des aménagements divers dont un système de drainage occupent en effet les deux tiers est de l'emprise, sans pour autant dessiner d'organisation exploitable. Aucune trace d'habitat n'est en tout cas à relever en dehors du petit secteur antique ; la zone a fait l'objet d'aménagements ruraux et agricoles successifs, réutilisant maintes fois les matériaux de construction prélevés sur le site antique et, en premier lieu, des galets peu porteurs d'informations chronologiques. 
5 Enfin la route menant à Proméry aux Temps Modernes et condamnée fin XIX ${ }^{\mathrm{e}} \mathrm{s}$. a été atteinte en limite nord de l'emprise; les galets qui la composent affleurent encore aujourd'hui en surface.

INDEX

Index chronologique : Antiquité romaine, ép contemporaine, Temps Modernes Index géographique : Rhône-Alpes, Haute-Savoie, Pringy operation expertise (EX)

\section{AUTEURS}

KARINE RAYNAUD 